\title{
RE-DISTRIBUTED CONSUMER DESIRE IN DIGITAL VIRTUAL WORLDS OF CONSUMPTION
}

\author{
Janice Denegri-Knott (corresponding author) \\ Bournemouth Media School, Bournemouth University \\ Weymouth House, Talbot Campus, Fern Barrow Poole, Dorset BH12 5BB \\ EMAIL: jdknott@bournemouth.ac.uk \\ Tel: 01202965516 \\ Mike Molesworth \\ Bournemouth Media School, Bournemouth University
}

\begin{abstract}
Janice worked in the not for profit sector after completing her undergraduate studies in communication and development at the Universidad Católica Boliviana. Shortly after that she earned a masters in marketing communications from the Bournemouth Media School and went on to gain her PhD from the Business School at the University of Exeter, England. She teaches consumer culture and behaviour at the Bournemouth Media School and is part of the Emerging Consumer Culture Group (ECCG). Her research deals with the structuring of consumption patterns and practices in digital virtual spaces. She has recently co-edited, Digital Virtual Consumption, a collection of essays that deal with these issues. She has also worked with major UK brands on projects dealing with the valuation and capitalization of digital content.

Mike is Senior Lecturer at Bournemouth University, UK. He has a $\mathrm{PhD}$ in consumer culture and currently teaches consumer culture and online marketing and is a member of the Emerging Consumer Cultures Group (ECCG). He has published in the areas of consumer culture, especially the consumption of digital technologies, the imagination in consumption and the marketization of higher education and the student as a consumer.
\end{abstract}

Acknowledgements: We would like to recognise and thank the efforts of our research students at Bournemouth University in helping complete this project. In particular we would like to thank Francesca Bennett, Lucy Bookham, Rebecca Dive, Gemma Hosking, Ben Jordan, Natasha Richardson, Samantha Stockwell, Chira Tochia and Rebecca Watkins for their helpful assistance. 


\section{ABSTRACT}

The aim of this paper is to discuss and illustrate how the use of software available in digital virtual worlds of consumption, including wish lists, watch lists and digital virtual goods (DVGs) interact with consumer desiring practices. We draw on a data set of three interpretative studies with technology users living in the South of England. We note the emergence of software-human hybrids where various aspects of competence in and commitment to desire construction, maintenance and actualisation are distributed between subject and software, leading to new configurations of consumer desire. We bring to the fore the often neglected role of nonhuman agents in the practice of consumer desire and highlight the potential breaks caused in the assemblage of the practices unfolding in digital virtual worlds of consumption. Our study shows new ways in which consumer desire practices are re-assembled in software-human hybrids, thereby enhancing our understanding of the role of nonhuman agents (software) in consumer desire practices. It also contributes a finer understanding on how software used in the construction and actualization of desire ultimately reconfigure consumer desire practices into a management process, where the focus is not daydreaming activity or material commodities per se, but rather the software itself. Here, the software not only presents things to be desired, but also absorbs some of the skill and competence needed to conjure up desire. Ultimately these configurations appear to create breaks in the experience of desire that weaken the hold previously binding consumers to objects of desire.

Key works: digital virtual consumption, consumer desire, human-nonhuman hybrids, eBay, wish lists, videogames 


\section{RE-DISTRIBUTED CONSUMER DESIRE IN DIGITAL VIRTUAL WORLDS OF CONSUMPTION}

\section{INTRODUCTION}

Involvement with online digital virtual worlds has increased to a point where KZero (2012) reports $2000 \mathrm{~m}$ registered users of over 100 different virtual worlds globally in the first quarter of 2012. Many of these worlds contain digital virtual goods (DVGs) as objects of desire for users and a focus of their activity. For example, we see shopping within Habbo Hotel, Second Life and World of Warcraft for exotic goods that are improbable, or unaffordable in material reality as a significant part of the experience. Numerous videogames invite similar practices, including a desire for exotic cars, weapons and more everyday items (for example in Forza, Gran Turismo, Everquest, Animal Crossing, or The Sims). In the US alone $49 \%$ of households own at least one dedicated videogame console (ESA, 2012) and in the UK this is 60\% (Mintel 2012). In addition, even more mundane (but also more popular) online environments like retailers and auctions sites are being recreated as spaces for such practices through software-based shopping aids like wish lists and watch lists. Amazon has an established 'Wish List' function, eBay allows auctions to be 'Watched', and Google lets users keep a 'Shopping List'. Doubleclick (2011) claims that Amazon.com alone has $110 \mathrm{~m}$ unique users and eBay.com has approaching 90m unique users each month.

Taken together we see a range of software that has the potential produce complex digital virtual consumption experiences. Given the greater use of website functions and videogames, we argue that these digital virtual worlds of consumption warrant inclusion, or even a primary focus when considering changes in consumption practices that result 
from the ambiguity of DVGs as liminal objects that are somewhere between only imagined and actually material (Denegri-Knott \& Molesworth, 2010; Denegri-Knott \& Molesworth 2012; Denegri-Knott, Watkins \& Wood, 2012). The aim of this paper then, is to examine this broadened range of digital virtual worlds, recognising specifically how virtual world, website and game functions (which we will collectively refer to as 'software') interact with the imagination and subsequent consumer desire and actualisation.

While previous research on consumer desire acknowledges the media (advertising, speciality magazines, catalogues and window displays) as a resource for fuelling desire, often their role is neutralised (e.g. Belk, 2001; Carrier, 1995; Clarke, 1998; Stevens and MacLaran, 2005) and consumer agency, privileged. Here we argue that software is capable of taking on various aspects of established desiring practices that might previously have been thought of as contained within the agency of consumers. As with other Actor Network Theory studies into consumer practices like family ownership (Epp and Price, 2010), DIYing (Shove and Watson, 2008) freezing (Hand and Shove, 2007), Nordic walking (Shove, 2005) and online investing (Zwick \& Dholakia 2008a; Zwick \& Dholakia, 2008b) our approach is to map out the interaction between human and nonhuman agents. In doing so we provide a new insight into the role of nonhuman agents in the production and maintenance of consumer desire. More specifically, we note the emergence of software-human hybrids where various aspects of competence in and commitment to desire construction, maintenance and actualisation are re-distributed between subject and software, leading to new configurations of consumer desire. 


\section{CONSUMER DESIRE AND DIGITAL VIRTUAL REALITY}

There is a tradition in consumer research that sees material consumption resulting from attempts to actualise what is conjured up through daydreaming (Belk, 2001; Belk et al. 2003; Campbell, 1987; McCracken, 1988). For example, Belk, Askergaard and Güliz’s $(1996,2003)$ work on passionate consumption is based on an analysis of desire in the fields of psychoanalysis, cultural anthropology and sociology. Their multi-disciplinary reading recognises consumer desire as a cyclical, highly pleasurable experience resulting from internalised moral codes deployed by consumers themselves as a means of selfmanagement (Foucault, 1976; 1977). These codes create the conditions necessary for desire to take place. On the one hand, by framing certain activities and goods as taboo, they intensify the draw of their actualization in consumption. On the other, they block the actualization of desire in material consumption by framing them as illegitimate or immoral pursuits. So, while consumers curb many desires, they also undertake selfseduction, imagining ideal, culturally validated lifestyles and pursuits first (Belk et al., 2003; Campbell, 1987; Jenkins, Nixon and Molesworth, 2011; McCracken, 1988) and finding suitable goods to help substantiate them. Such goods must be 'just out of reach' but not unobtainable in order to allow the distance necessary to inflame a desire while at the same time sustaining the hope that a yearned for outcome is possible (Belk et al. 2003; Campbell, 1987; McCracken, 1988). Here it is not the good per se which is desired, but rather an imagined lifestyle or state of being that is now associated with the good (Belk et al. 2003; Campbell, 1987; McCracken, 1988). McCracken (1988) defines these desired outcomes as displaced meanings. These are precious meanings which are purposefully removed from the here and now and placed in different out of reach 
locations in time and space, like golden pasts or exciting futures, or even different countries, to avoid being tested. As anticipation and longing are what makes desire so enjoyable, eventual consummation through purchase of goods often results in disappointment caused by the loss of desire. The longing for a desiring state triggers a new cycle of desire for yet another purchase (Belk et al. 2003). Material consumption is therefore framed as only the culmination of a cycle of desire, with virtual consumption (that which takes place in the imagination) as the privileged site of pleasurable preconsumption activity. This whole process has been defined as a hedonic, artistic enterprise and therefore highly affective (Campbell, 1987; McCracken, 1988) and very different to need satisfaction through rational decision-making (Belk et al. 2003).

This understanding of consumption also invites a further consideration of what we understand as 'real', and of what is required to actualise desire. For example, Shields (2000; 2002) challenges the taken for granted separation between the material, privileged as 'real', and the imagination as 'not real', by arguing instead that the virtual, which includes pure thought and idealism, should be understood as both real and ideal (the imagination as 'ideally real') and as entwined with our perception of 'everyday', material reality (the material, in contrast, may be thought of as 'actually real'). His work in part, maps out in history the virtual as a significant cultural category. Rituals, fictions, simulations, games and architecture can be seen as historical types of virtual realities designed to transport us somewhere else. As virtual worlds have long existed in myths and fictions, we should more accurately describe computer-generated worlds as digital virtual worlds. Like the actually real however, the digital virtual realities of virtual worlds may also fulfil the function of making present the ideal (Shields, 2002). 
The digital virtual opens the field of consumer desire research to the study of an interim location that is potentially both ideal and actual, that not only could enhance consumers' capacity to construct desire but also their ability to actualise it (DenegriKnott, 2010; Denegri-Knott \& Molesworth, 2010; Molesworth \& Denegri-Knott, 2012). Drawing on Shields's $(2000,2002)$ theorisation of the digital virtual as a liminal (Tuner, 1988) space - somewhere between the imagination and the material - we label these practices as digital virtual consumption (DVC). The ontological stature of the digital virtual as liminal or an 'in-between' place allows consumers to experience new forms of 'almost owning', as items saved in shopping lists or DVGs in videogames and online virtual worlds act as proxies of materially real goods. We should note that DVC differs from virtual or imaginary consumption (for example a daydream) inasmuch as the object of consumption does not only reside in consumers' minds, and therefore lacks the autonomy of individuals' imaginations, but is experienced as owned and used within the parameters of digital virtual spaces. The result is the possibility for new practices relating to cycles of desire and actualisation.

\section{HUMAN-SOFTWARE HYBRIDS AND THE PRACTICE OF DESIRE}

Desiring may be considered an important consumer practice involving the conjuring up of imagined realities and then attempts to actualise them. As with all practices this consist of a series of interconnected elements, namely forms of mental and bodily activities, things or technologies and their use, know-hows as well as motivational knowledge and emotional states (Recwitz, 2002; Schatzki, 1996). Whilst Warde (2005) and others (Shove and Pantzar 2005; Warde, 2005) see consumption as a moment in 
almost every practice, precise definitions of what constitutes a practice are elusive. Here we focus on the various practices involved with and facilitated through the use of software that are related to cycles of consumer desire. These include how consumers and software together develop competences to know what is desirable, find things to desire and to 'manage' the cycles of desire including its actualisation.

In order to better understand these new practices, we now discuss the distributed nature of competences and commitments that are formed through software-human hybrids in their assemblage (Bettany \& Daly, 2008; Kerrane \& Bettany, 2011; Hand \& Shove 2007; Lehtonen 2003; Watson \& Shove 2008;). In Actor Network Theory, (Latour, 1992, 2007) all human and nonhuman participants are understood as ontologically equal, and agency is distributed across networks of objects, bodies and other heterogeneous entities. There is also recognition of actor-networks in consumer practices that place greater emphasis on the potential agency of things especially where new technologies of all sorts allow for the redistribution of competences (see Dant, 2005; Hand \& Shove 2007; Lehtonen 2003; Watson \& Shove 2008). This strand of thought qualifies such networks as human-nonhuman hybrids. Watson and Shove (2008) use the classic example of a person and a hand tool as an enhanced entity capable of different capacities as a starting point to argue that competence and skills are distributed across human and nonhuman entities. They note how DIY involves the skill of craftspeople being taken on by DIY products such that DIYers are able to undertake tasks that they would previously lack the skills to achieve. The point is that practices like DIY painting have not become less skilled, and do not hold less agency, but rather that there has been in effect a re-distribution of skill between people and technology, where DIY products 
have absorbed some of competence and knowledge, and therefore agency, previously embodied in the individual carrying out home renovations. Unlike phenomenology that focuses on the experience of the human agent only, ANT allows us to better recognize that practices involve, and evolve, through the agency of both humans and nonhumans.

Human-nonhuman hybrids are composed not only of an assemblage of skills and competences but also commitment or levels of affect (Denegri-Knott \& Zwick, 2012; Schau, Muniz Jr. \& Arnould, 2010; Knorr Cetina, 2001; 1997; Schatzki, 2001). Level of commitment or emotion is a constitutive component of what Schatzki has called the teleoaffective structure of practices. While our engagement in carrying out a practice is underpinned by the impetus to complete a project or at task, our desire to carry them out is motivated by a broader end or purpose (Schatzki, 2001; 1996). We engage in certain practices because it matters to us, and this makes completing certain tasks and projects emotionally charged affairs and not just an exercise in applying knowledge and skill. Mattering, as Schatzki (1996, p.123) further explains 'structures the stream of behaviour" and 'it achieves this by affecting either which possibilities of existence a person is out to realise or what makes sense for him to do so'. As it has already been noted in the consumer desire literature, consumer desire practices have an affective component because they are set in motion by end purposes and desired states of being that matter deeply to individuals (Belk 2001; Belk et al. 2003; McCracken, 1988; Stevens \& MacLaran, 2005) Here, however, we see that the affective component of consumer desire practices are usually seen as being located within the agency of the consumer only. As we consider consumer desire in digital virtual worlds of consumption, we question this assumption. 


\section{METHODS}

We draw from three studies undertaken with technology users. The first was a study of 24 adult videogame players conducted in 2006 (including adults who play in digital virtual worlds such as World of Warcraft and EVE online); the second, a study of 40 avid eBayers, conducted between 2008 and 2010 and the third (undertaken by student research assistants), was a study of 20 wish list users, completed in 2012. All studies used indepth interviews and took place in the South of England. The interviews adopted a phenomenological perspective which privileged our participants' lived experiences and aimed to produce 'thick descriptions' from which understanding of how such experiences were meaningfully constituted and communicated by respondents could be purveyed (Creswell 2007, Goulding 2005, Thompson et al.1999), but also dealt with the specific practices involve in generating these experiences. Within the first two studies practices relating to desire for DVGs and interactions with software as part of such practices emerged as key themes. The focus on participants' life worlds also allowed such stories to be elaborated to include comparisons with other aspects of these lives, including online shopping and material consumption practices. The third study focused specifically on the use of wish lists on Amazon, and retailers like Topshop and ASOS. Together these three studies allow a wide range of experiences of DVC across different software platforms to be considered.

Most of the interviews were held at respondents' homes, with participants usually logged onto the Internet and having access to goods saved in wish lists, videogame accounts and user profiles. In total approximately 150 hours of data was recorded. Data 
interpretation took place by way of a hermeneutical circle involving a part-to-whole reading, made up of individual interpretation of interviews at an ideographic or individual level and cross-case analysis. This approach enabled us to identify both participants broader and biographical experiences of consumption, (including their moralized hopes and aspirations from which specific consumer desires are constructed), and the specific descriptions of using software within such projects. From this exercise thematic descriptions of experiences were derived (Thompson et al. 1989) and linked to practices. Syntheses then followed to identify common structures or global themes in the experience, which were then built upon for theoretical elaboration.

\section{FINDINGS}

In making sense of how digital virtual world software helps to create and actualise consumer desires, we discuss and illustrate (1) the ways in which skills and competences previously carried out by consumers are re-distributed in software-human desiring hybrids, (2) the potential for this to result in changes in the focus of desire, and (3) the implications of these new practices for the affective experience of desire. We see this amalgamation of consumer investment and skill with technology affordances, which are technological properties that enhance action possibilities for users (Suthers, 2006), as producing knowledge projects for consumers, or epistemic objects of consumption (Zwick \& Dholakia 2008a; Zwick \& Dholakia, 2008b) that result in change in the practice of consumer desire, recognising that under these circumstances our existing understanding of the cycles of desire (imagining, focusing of a consumption object, then actualization through material consumption) may be transformed. 
In-keeping with Shove and her colleagues' (Hand \& Shove, 2007; Watson \& Shove, 2008) observations, practices associated with the feeding and actualisation of consumer desire, just like painting and freezing, are achieved in situ and are made up of distributed competences scattered across the user and the technology which are mobilised to achieve a certain goal or project (Schatzki, 1996; Watson \& Shove, 2008).

\section{Re-distribution of the skills and competences required to construct desire}

Consumer desire requires a steady supply of things to want (Belk 2001; Belk et al. 2003; McCracken, 1988; Stevens \& MacLaran, 2005). Consumers must connect imagined hopes with specific goods, drawing from marketing materials and shopping experiences. As Campbell (2004) points out, consumers test the wide range of goods in the market for their potential to connect to projects of desire. The ability to find goods that are capable of producing desires becomes a key skill in linking daydreams to consumption such that the pleasure of desire may be experienced.

Often engagement with digital virtual worlds involved 'wanting things', but here our participants tell various stories about how the task of finding things to want may be taken on by software. We illustrate with examples from videogames, online retailers, and collectors on $e B a y$. In each, aspects of the skills and competences required to experience desire are re-distributed to software such that there is less required human agency.

\section{How videogames present desirable items to players as they progress through levels} Playing videogames may involve the search and acquisition of new commodities to be won or bought. Ann, a mother in her mid-30's who played World of Warcraft explained 
how she enjoys shopping for items in the game. This she described as both frustrating (because she can't afford the 'best stuff') and exciting. At one point she shared a story about playing the game with her brother who has a much higher-level character:

'...and my brother will like just go round inspecting people and say 'Ah look at that Armour Ann, that is like', I've forgotten what it is, it's not elite, it's purple, the words are purple which means it's like extra special-and like 'yeah, that's the druid outfit and one day you can get that', and all this kind of stuff.'

Later, Ann reflected on how the game presented her with future desirable items. She told us how higher levels and certain character types can use certain items such that the software decides which items a player should want next, for example the druid outfit cited before. Other players described a similar situation in other games. For example in driving simulations progression in the game requires that faster cars need to be bought to compete in more difficult races. The task of conjuring desire from market offerings is therefore made easy as the next item reveals itself as players progress in the game.

This revelation of things to want is evident in Daniel's frantic search for Earth Defence Force 2017 weapons. During his interview, Daniel, an interactive media student, explained how things that he wanted were determined by the games he was playing. He judged his own desire for DVGs as a reflection of the level he had attained in a game. That meant that in order to achieve progress, the videogame focused desire on certain objects. One year he and one of his friends had decided to complete Earth Defence Force 2017. They soon found out this required them to have certain weapons: 'Me and my friend decided that we would try and complete it last year and it's got 50 levels and we wanted to do it on every single difficulty and there's 5 
difficulties.... and it became apparent that we didn't have good enough weapons to complete it. Like, we literally tried as hard as we could and then we looked around on the internet and people were saying you need to have this gun, if you don't have this gun it's pretty much pointless. Because this gun is gonna make you win and if you don't have it it's really difficult.'

For Ann and for Daniel, the range of things to desire is narrowed and pre-focused by the game. The result is that they don't need to put effort into searching for things to want, matching them to ideals. Rather the game presents both the goal (for example, the next quest or level) and the desirable item that should be hoped for.

\section{How retail websites present desirable items to shoppers}

Other participants habitually visited online retailers in search of new things to want, either by exploring a site's personalised recommendations, 'what's new' sections, or what other users had bought. Like videogame worlds then, these digital virtual worlds can be qualified as knowledge projects for consumers (Zwick \& Dholakia 2006a, Zwick \& Dholakia, 2006b) because they reveal themselves progressively through interaction, use, examination and evaluation. Since they are always in the process of being defined and acquiring new properties as they shed old ones this makes them an optimal source for things to desire. Differently put, what can be desired is always in a state of flux, with new objects appearing through further exploration and interaction with digital virtual worlds.

The way in which software acts to present desirable goods to consumers is illustrated by Matthew's use of $e$ Bay. Matthew is happily married, has a teenage son and 
works in software engineering. When we interviewed him he was immersed in refurbishing a 20-year-old caravan he had bought on $e$ Bay. He retold the lengthy process he followed in purchasing the caravan highlighting how he obsessively visited $e$ Bay, waiting for 'the right caravan to appear', and how the search itself had helped him define what kind of caravan he really wanted and how much he was willing to pay for it. Here we see how a chain of structure of wanting unfolds, binding Matthew and $e$ Bay into objectual practices (Knorr Cetina, 2000), in which Matthew invests psychic energies in animating the unfolding of desire, and is rewarded with exciting, new possibilities of 'better' things to buy. Knorr Certina uses the concept of objectual practices to explain the dynamics binding human and nonhuman agents in the process of discovery. In that relationship objects establish and make visible a chain of wanting by signalling what they still lack, and the subjects, who animate them, are responsible for progressively opening cycles of discovery and evaluation.

Matthew awards the software agency in presenting him with things to want, reducing how much effort he needed to find desirable objects. He told us how even when he searched for specific things, a whole range of other things came out in the search results that he had never considered:

'I love the search mechanism on eBay where you think of the keywords that describe what you're after. You type them in and it'll give you a few examples and then you think, well, actually that's not quite what I want so you refine your search and type it again. Then suddenly not only have you found what you want but sometimes there's something that's actually a little better than what you had in mind to start with'. 
The way in which the software is perceived as capable and responsible for conjuring and actualising desire is also well illustrated in a young married couple's use of $e$ Bay to purchase KitchenAid appliances. Husband and wife, Mike and Faye enjoyed baking and cooking in general and had been using $e$ Bay to source an affordable food mixer. During our interview he described eBay as 'dangerous' because 'it made you buy things you didn't need':

'You type in KitchenAid and we wanted a cream one because it'd complement everything. So you type in KitchenAid cream and it brings up KitchenAid ice cream maker and KitchenAid cream coffee machine and Kitchen Aid cream burger grinder. You almost picture where you're going to put it. You think, well, the mixer could go there and the food processor could go in there but come out there, and the coffee machine could go in that corner and the kettle could go there and the four slice toaster could go there. Before you know it you could quite easily have spent $£ 2 / 3,000$ on fitting your kitchen out with things that actually you don't need because the cooker works and the coffee machine works.

eBay was presenting him with KitchenAids to desire. 'You've looked at things that you didn't know you wanted but now you think actually I do want that, and you'll save the money up for it.', he added. In this way he is suddenly not only considering owning a food mixer, as he first originally intended to, but all sorts of other appliances. In incorporating those wants co-constructed with $e B a y$, he even starts to picture how this range of KitchenAid articles may look in his kitchen. 


\section{How eBay presents desirable items to collectors}

A more complex re-distribution of skills and competences was noted in more knowledge intensive, and arguably, emotionally engaging practices, like collecting. When we spoke to Richard, a 43 year-old professional working in the aeronautical industry, he had almost finished an eight yearlong project to collect miniature cars. When he first started, the collection grew slowly as he had to visit shops and specialist festivals, but once he started to use $e B a y$, his collection grew quickly. He told us:

'... eBay's made it much easier. I mean just taking those cars for instance, most of them are Ferraris and most of them are Michael Schumacher's Ferraris, the ones he's won his championships with. So I'm looking for that specific car and it's very difficult to find it in the shops locally. You'd probably find it at somewhere like Goodwood events, Festival of Speed, something like that, that the traders would go to that show, so you'd find it there. But again you've got to go there whereas if you buy it on eBay the postman will come and deliver it to your door, it's so much easier. It's easier as well to find things, especially the rarer ones that you just wouldn't find in the local shops if someone's got one for sale'

He had devised a series of search tactics to find desired goods, the latest included the use of an automated system of $e$ Bay email alerts. Such systems constitute a delegation of searching competence, where the search is being entrusted to a software agent that transforms the practices that previously made up collecting. Here we observe how the skill of operating the software replaces other more complex skills once necessary to achieve his goals. For Richard and other collectors, this meant not having to visit 
specialist shops, car boot sales or fairs. For other participants like Natalie, a 22-year-old sports student, learning how to use eBay filters competently, meant that fully understanding an object of desire was no longer necessary. Natalie had an obsession with watches and she often visited eBay to search for them:

'I would literally type in yellow watch...I'd start with that and then underneath they have related searches, so here they've got yellow watch Casio and I'd maybe think oh yeah that's what I want, or they've got yellow Ice watch, so initially I'd probably start it off quite simple and it's only when I start seeing things...initially I'd say I'm looking at the watch um, and then say I like this Casio watch I'd think, hmm [£]3.89 I wonder if I can get that better. So then I'd go back up to the top because they've given me the idea of a Casio, so then I'd go yellow watch Casio. And then it's not a case of looking at the watch it's a case of looking at which I'd get the best value for... so you can sort it out by however you want, it automatically goes to best match...'

Here we note how the software presents the 'best' item and how judgments that may have involved considerable research and application of specialist knowledge are now undertaken by the software that presents users with the things they should want.

Throughout these examples we see the various ways in which the knowledge and skill required to practice consumer desire is re-distributed. Software is capable of providing a context in which DVGs are wanted and then appropriate goods as desirable in the case of videogames, but retail and auction sites are also capable of something similar. Through simple searches much of the effort in deciding what should be wanted, and then finding suitable goods is undertaken by the software. We now consider the implications 
of these transformations in desiring practices.

\section{Re-focusing of desire in digital virtual worlds of consumption}

For our participants, videogame experiences often constituted the actualisation of an ongoing daydream, for instance driving fast cars, adopting a different, more exciting persona or playing professional basketball (see Molesworth, 2009). The focus of desire here moves from materially real goods to DVGs. Mandy's experiences are illustrative of this re-focusing, where desire becomes anchored in the digital virtual space. Mandy is a web developer in her mid 20s. She lives with her boyfriend in a small apartment and at the time of her interview she was very involved in interior design. She told us:

'I am very much into interior design anyway. I'm doing an open learning course in interior design, so I'm thinking, you know, I'm just going to apply it to my game as well, so, you know, if my own flat is matching and co-ordinated, I want my house in my Animal Crossing world to be matching and co-ordinated as well...To be honest at the moment, obviously, I'd say my animal crossing game is more important than the course.... Yes, so I have all my themes, like my back garden theme and my western theme, a beach theme and a camping theme...'

The focus becomes the game rather than her material home. She explains that she has a number of different rooms in the game; each with a different theme and the game presents a whole range of items that together complete the theme. Her interest is the predefined items presented by the software, working to complete the themes within the game, rather than focusing on any one desirable DVG. 
However, while in videogames desire is pre-focused by the software, in other online digital virtual spaces there is the potential for many more items to be presented as desirable though search and recommendations than can be bought. Here it is the website architecture which focuses desire on certain items. Steph a 22-year old student we interviewed, described the always-changing status of her wish list and how often she needed to update its contents in light of newly listed items which were prominent features of the websites she visited:

'It's always going to be something that's new in... like on Topshop and ASOS. They update their new in section about I'd say...every week? I go on at least every day so it's not hard to find something that I can update my wish list with on the new in, plus I don't like, really like anything that's not new, you know?...' As Steph puts it, there 'is always going to be something new on Topshop and Asos', and because she is cognisant that the site will be updated on a weekly basis, her attention is focused on the new, rather than on saved items.

Our participants experienced this readily supply of goods to possible desire as a 'burden' to be met with technology affordances provided by software. Often our participants told of various management processes involved in keeping wish lists updated and DVGs organised to ensure that objects stored still 'spoke' to them (see also DenegriKnott et al., 2012). This use of technology is akin to the use of attics and other 'cooling off' spaces described by Grant McCracken (1988), in that they act as temporary locations where ambiguous items can be stored while a decision can be made regarding what should be done with them. Unlike common 'cooling off' spaces like attics that are seldom visited by homeowners, wish lists are routinely visited to see if items still 'speak' to 
them. Like attics, however they are used to reduce an item's 'emotional heat', making it less engaging, thereby re-distributing affect from users to software. We now turn to this redistribution of affect.

\section{Re-distribution of affect in digital virtual worlds of consumption}

Much of the literature where consumers are presented as engaged in anticipatory daydreaming qualifies their experiences as intrinsically rewarding and purposefully sought (see Belk, 2001; Stevens \& MacLaran, 2005; Denegri-Knott, 2010). However, the configuration of desire in human software hybrids is different. In previous work (see Denegri-Knott \& Molesworth, 2010) it had been assumed the use of wish lists and consumption of DVGs might ultimately lead to heightened states of desire that would

culminate in material actualisation. We found instead that the re-distribution of desire across human and nonhuman agents resulted in a reduced level of commitment to actualising consumption intentions in the materially real.

In recalling their past experiences, our participants described how they acquired skills to manage wish lists, set up email alerts and auction snipping software so that they didn't have to think about items they wished for. This can be seen as a re-distribution of affect or commitment, where technology users share the practice of desire with nonhuman agents. Using examples from a range of websites we include participant stories on how engagement with software aiding consumer decision-making creates engagement with the technology rather than the items desired. 


\section{How software use reduces commitment to desired items}

Jack, a 21-year-old product designer, culled goods that no longer 'spoke to him.' During his interview he revealed he was concerned with how messy his wish list could get given the fluctuation of his own changing taste:

'I usually find is I'll put stuff in there that's on a whim sort of wanting it, put it in there, forget about it and then I'll have a sort of clear out and quite a lot of the time it's out of stock anyway so I'll just delete the bookmark... Sometimes I'll find a pair of trainers and I'll bookmark them, and then another pair will be released that are nicer and it'll be like, that one will come off and the other one will go on... [Most items that get taken off the wish list] get replaced [rather than purchased], yeah, definitely replace most. Yeah, I can't normally afford the stuff on there...None of the things that are on there at moment will probably be on there in six months time it'll probably all be replaced'.

Jack's saved items can be usefully qualified as liminoid objects, that is objects that are somewhere between ownership and non-ownership and as a result are charged with reflective potential (Denegri-Knott \& Molesworth, 2010; Molesworth \& Denegri-Knott, 2012; Denegri-Knott et al., 2012). As such they are at the centre of series of management procedures where items are routinely moved around so as to question their ability to produce an emotional response (see Campbell, 2004). In Campbell's narrative, emphasis is placed on the ontological function facilitated by shopping. He argues that we discover who we are by testing our reaction to commodities found in the marketplace, noticing our likes and dislikes. Placing items in wish lists seems to aid in the fine-tuning of likes. Note how Jack tests his desire for a pair of trainers by comparing them to new releases, which 
he ultimately judges as 'nicer'. Over time however, exposure to these liminoid items appears to produce satiation; as Jack later told us, over time saved items in his wish lists looked a bit boring.

For other users the use of technology, like Auction Sniper on eBay, was perceived as reducing the overall engagement with the process of acquiring desired items. Pete, a 22year-old sports student, told us that he used Auction Sniper because he wanted to avoid getting involved in emotionally draining bidding wars or having to think about the items he wanted to buy once the decision was made:

'I use a tool called auction sniper... Whenever I bid on eBay, or almost whenever I bid on eBay I will always use this...I don't have to keep checking up on the same item to see what price it's going for, so basically it means I'm always looking for new items not the same ones, and it means I don't get into bidding wars with other people for the same item. So, I found that jacket, and I set up the snipe for it, and then I knew that I didn't have to worry about when the item was ending or how high it was going, I could just ignore it and I literally just get an email from them when it's ended saying you either won it or you didn't.'

Reflecting on his use of this tool, he later revealed that even if 'it sounds weird... you can get attached to an item otherwise, if you get in a war you want to win it, but with this it removes that emotional attachment.'

Steph a 22-year old student we interviewed, described the always-changing status of her wish list and how often she needed to update its contents: 'It's always going to be something that's new in... like on Topshop and ASOS. They 
update their new in section about I'd say...every week? I go on at least every day so it's not hard to find something that I can update my wish list with on the new in, plus I don't like, really like anything that's not new, you know?... Obviously some things do stay on there but, most of the time I buy those things that are on there for over a week anyway, like my new coat!'

In Steph's narrative, we see her testing stored items against new updates. As noted elsewhere (Denegri-Knott \& Molesworth, 2010; Molesworth \& Denegri-Knott, 2012; Denegri-Knott et al. 2012) saved items in wish lists can be usefully qualified as liminoid objects, that is objects that are somewhere between ownership and non-ownership, and as a result are charged with reflective potential. As such they are at the centre of series of management procedures where objects are routinely moved around and arranged so as to question their ability to produce a desired emotional response (see Campbell, 2004). Luke, a 24 year graduate who was starting a personal business, reveals how he would routinely return to his wish list to find that what he 'really, really wanted' no longer appealed to him. Similarly, others like Jack, a 21-year-old product designer, found himself culling goods that no longer spoke to him. During his interview he revealed he was concerned with how messy his wish list could get given the fluctuation of his own changing taste:

'I usually find is I'll put stuff in there that's on a whim sort of wanting it, put it in there, forget about it and then I'll have a sort of clear out and quite a lot of the time it's out of stock anyway so I'll just delete the bookmark... Sometimes I'll find a pair of trainers and I'll bookmark them, and then another pair will be released that are nicer and it'll be like, that one will come off and the other one will go on... [Most items that get taken off the 
wish list] get replaced [rather than purchased], yeah, definitely replace most. Yeah, I can't normally afford the stuff on there...None of the things that are on there at moment will probably be on there in six months time it'll probably all be replaced'.

These examples suggest that software-human desiring hybrids bring about new ways of practising and actualising consumer desire, where users purposefully remove themselves from the process of desiring, delegating affective investment to the software.. The sense of almost own seems to produce partial actualisation that may reduce the need for material acquisition. In addition to this, these practices, centre not on animating the object's ability to seduce, but rather, shift the focus of desire from object to software maintenance. The desire for the 'best' wish list replaces a desire to buy the items such a list contains.

In such cases we could argue that desire was no longer perceived to be held only in the mind, but rather in the software itself.. Similarly, in videogames, players don't need to conjure desire for items, rather the software presents them as already desirable, and players complete the collections that the software wants

\section{How software desire on behalf of users}

Andrew, a young university student who enjoyed clothes shopping, explained how he had used his Amazon wish list to avoid having to think about a pair of expensive jeans he had wanted:

"Well say I see something in the shops, most recently a pair of Diesel jeans that I wanted there and then, however at $£ 120$ I say no more. I was able to try them on and imagine myself wearing them on a daily basis that made me want them even more... I questioned whether jeans are worth that kind of money. I used my red 
laser bar code scanner (an iphone app) to find if the jeans were cheaper

anywhere else online, which they weren't, and put them in my Amazon wish list

extension.... It was becoming a burden to have to think about the jeans. So I

thought by dumping them in there I don't have to imagine or think about them

because they are easy to get to if I feel like looking at them".

Rather than prolonging the anticipatory daydreaming accounted in previous research

(Belk et al., 2003; Campbell, 1987) potential desired objects were simply dumped in lists as a way not to think about them. Note how Andrew decides that it was a 'burden to think about the jeans' so he dumps them in his wish list. He did so in the knowledge that the jeans were save in his list, available for him to retrieve at any time; as he puts it ' $I$ don't have to imagine or think about them because they are easy to get to if I feel like looking at them'. Caroline, a 45-year-old office worker, also told us how once she knew a James Patterson book was coming out, she would quickly include it in her wish list so that it 'would remind her'. Like Caroline, other technology users, purposefully placed items in lists or used auction sniper technologies so that the burden of thinking and desiring was left to the software, in a set of practices not dissimilar to those that Tian and Belk (2005) describe as the use of 'prosthetic objects' in the workplace. These technology affordances provided by software can be seen as transforming software into extensions of one's mind' or 'cognitive enhancements' (Bostrom and Sandberg 2006) that can free up the human agent to engage in other activities. This then seems to transform the teleoafffective structure (Schatzki 1996) of desire practices, making the affective component less salient, and altering the focus from end purposes to being more task or project orientated. 
This could be problematic for the experience of desire. What makes desire so alluring is the fact that it is emotionally charged, intense and passionate and above all, unmanageable (Belk et al., 2003), but with affect being reconfigured in new human software hybrids, it produces just that; a streamlined, managed process. This rationalisation of consumer desire was particularly problematic for the collectors we spoke to. Part of the pleasure of collecting includes the anticipation of finding something and the slow process of research requiring the accumulation of knowledge of the value of items and where they can be found. Such competence is now taken over by software, facilitating, but potentially also undermining the pleasures of collecting as what may once have taken years can be achieved in a matter of weeks. As Mike and his wife Faye told us, the speed and ease with which collections were started and completed, contributed to a waning of interest. Amongst the now defunct collections the couple had accumulated within a couple of years, there were signed baseballs, signed books, Glow Worms, Cornish ware and Famous Five books, many now packed up in boxes in their loft. Mike recalled how his wife had gone 'on eBay and started looking at them [Glow Worms] and ended up spending $£ 5 / 6$ on each one and that lasted for a couple of months'. Faye soon got bored of it and moved on to her next collection. She had decided she wanted all the 25 books making up Enid Blyton's Famous Five series. She told us how she accomplished this goal quickly:

'It didn't take long, about four or five weeks because I just bought them in bulk so it was quite good. I was quite like that's it, I'm having that one, I'm having that one. You don't think about how much money you're putting on there, you just think, right, I've got to have that one so I just put in loads of money just to get that 
one so you've got it.'

Faye explained how eBay made it possible for her to acquire things that were previously unavailable to her. With her husband she had devised strategies to secure items, buying in bulk, bookmarking and monitoring availability of goods, setting up email alerts and bidding at the right moment. However, the experience had left her somewhat jaded. She thought the whole process had become a bit 'stupid'. At the end of the interview she told us she was 'not not doing it anymore' and 'that's it for now'. Paradoxically it would seem that the effort expended in becoming a more adept buyer added together with the sheer number of items available on $e B a y$, threatened the very fabric holding the experience of collecting and desire together.

\section{DISCUSSION}

Our study shows new ways in which consumer desire practices are re-assembled in software-human hybrids, where desiring is not only the preserve of consumers as dream artists, but rather a practice that happens in the coming together of human and nonhuman agents. Differently put, software allows for new ways of practicing consumer desire that take place as result of a redistribution of competences and affective investment. In this respect, the software may augment consumers' capacity to desire by enhancing the number of things that can be wished for, but also, may reduce the delay between decision-making and purchase that was where desire resides. One result is a focus on managing the components of lists and videogame resources as more tangible extensions of what resides in consumers' imagination.

This challenges the generally unquestioned autonomy of the individual in the 
fueling of consumer desire (Belk et al. 2003; Campbell, 1987) as well as problematising the experience of consumer desire itself. Although the relational character of consumer desire is implicitly acknowledged in consumer and marketing research (see Belk 2001; Belk et al., 2003; Carrier, 1995; Stevens \& MacLaran, 2005), agency is generally placed on the consumer, and external market resources like advertising are presented as resources used autonomously by consumers who construct anticipatory daydreams with them (Campbell, 1987; Belk, 2001; Belk et al. 2003). However, the increasing use of software in consumption moments is not only a possible resource to construct anticipatory daydreams as with other market resources (Belk, 2001; Belk et al. 2003; Steven \& MacLaran, 2005), but assembles different ways of practising desire. In accounting for how consumer desire is enacted in digital virtual worlds it may be useful to complement existing metaphors which present consumers and marketing agents as coproducing desire (Belk 2001; Belk et al. 2003; McCracken, 1988; Stevens \& MacLaran, 2005) with an analysis that brings to the fore nonhuman actors, in this case software and the kind of changes in practice they precipitate.

Our work offers insights on such changes by describing the functioning of these human-software hybrids, illustrating the ways in which skills, affect and focus of desire are re-distributed. In these software-human hybrids the software may stand in for searching, desiring and actualising efforts by human actors. Software replaces the tasks of finding, working for, buying and the labour of possessing and owning, but also imagines and desires on consumers' behalf, for example my presenting things that should be longed for and remembering those things that may still be wanted. However, the results are fragile and not always conducive to engaging, pleasurable experiences for 
consumers. The re-distribution of search skills and the absorption of affect by software seem to transform the teleoffective structure of desire practices, reducing the saliency of end-purposes, and making more prominent its task orientated dimensions. As we saw in our data, often the focus on animating the software was such, that the sought after life transformation hooked onto desired goods appear no longer to be focus of attention. What mattered, to borrow from Schatzki, in terms of what a desired good was meant to abridge (McCracken, 1988)- a better relationship, an altered state of being, recedes into the background, while the deployment of software needed to acquire it, comes into focus. It follows that desiring practices in digital virtual worlds are best described as punctual tasks or projects that need completion, rather than passionate consumption moments as those described in previous work (see Belk 2001; Belk et al. 2003; McCracken, 1988; Stevens \& MacLaran, 2005). Simply put, DVGs need to be owned to achieve progress in videogames, auctions won, and wish lists tidied up. Our participants often spoke about 'dumping' things in wish lists as a way not to think about them, thus re-distributing their level of commitment to a potentially desirable item from themselves to the wish list. With this delegation however comes a sense of achievement in realising a collection, a coherent wish list or a completed level of a videogame.

Our interviews with a wide range of technology users also provide us with a better understanding of how the actualisation of consumer desire in the digital virtual interacts with desire for material real consumption. A trajectory binding the digital virtual and actually real, material consumption was not always apparent. In fact, for most items wished for, bookmarked or won in videogame play, their consummation as things almost owned truncated trajectories towards material consumption. The sense of almost 
ownership seems to produce partial actualisation, which if anything, resulted in a reduction of desire to actualise in material reality. In a sense these spaces are contained, or semi-contained digital virtual worlds of consumption that bring together consumers and software to assemble new practices of desire that are unlike those previous documented and discussed.

\section{CONCLUSIONS}

Although the term virtual worlds is usually applied to online multi-user simulations, here we extend the term to include the digital virtual worlds of consumption conjured into existence through videogames and more mundane sites such as retailers and auctions. Digital virtual worlds of consumption are all those online spaces where consumers and software assemble cycles of desire for commodities (material or digital virtual). In the descriptions of our participant's lived experiences we have noted new configurations for consumer desire, where skills, competence and affect are scattered across humans and software, with software undertaking aspects of desire that were previously located in human agency, as humans take on new, often more rational management tasks.

Our study enhances our understanding of the role of nonhuman agents (software) in consumer desire practices. It contributes an understanding of how software ultimately reconfigures consumer desire practices into a management process, where the focus is not necessarily daydreaming activity or material commodities per se, but rather the software itself. Ultimately these configurations appear to create breaks in the experience of desire that weaken the hold previously binding consumers to objects of desire, and instead establishing objectual relations between consumers and software. This has significant 
implications for our understanding of consumer desire in general. In particular we noted the possibility that given the ease with which very large numbers of desirable objects may be identified, software may take on the role of desiring, whilst the consumer directs their attention to maintain, managing and reviewing this list of items that the software wants for them.

\section{REFERENCES}

Belk, R. (2001) 'Specialty Magazines and Flights of Fancy: Feeding the Desire to Desire'. In A.R. Groeppel-Klein \& F.R Esch (Eds), European Advances in Consumer Research: Vol. 5. Association for Consumer Research (pp. 197-202). Berlin. Retrieved from http://www.acrwebsite.org/search/view-conferenceproceedings.aspx? $\mathrm{Id}=11593$

Belk, R.W., Ger, G. \& Askegaard, S. (2003). The fire of desire: A multisited inquiry into consumer passion. Journal of Consumer Research, 30, 326-51. Retrieved from http://www.journals.uchicago.edu/

Belk, R., Ger, G. \& Askegaard, S. (1996). 'Metaphors of consumer desire', in Kim P. Corfman \& John G. Lynch, Jr. (Eds) Advances in Consumer Research, Vol. 23. Provo, UT: Association for Consumer Research, 368-73. 
Bettany, S. \& Daly, R. (2008). Figuring companion-species consumption: A multi-site ethnography of the post-canine Afghan Hound. Journal of Business Research, 61, 408-418. doi: 10.1016/j.jbusres.2006.08.010

Bostrom, N. and Sandberg, A. (2006). Converging cognitive enhancements in Bainbridge, W. \& Roco, M.C. (Eds), Annals of the New York Academy of Sciences, Vol: 1093 (Special Issue: Progress in Convergence: Technologies for Human Wellbeing, 201-227

Campbell, C. (2004). I shop therefore I know I am: The metaphysical basis of modern consumerism. In: H. Brembeck \& K. M. Ekström, (Eds.), Elusive consumption (pp. 27-44). Oxford: Berg Publishers.

Campbell, C. (1987). The Romantic Ethic and the Spirit Of Modern Consumerism, New York: Basil Blackwell Ltd.

Carrier, J. G. (1995). Presenting commodities in catalogues. In: J. G. Carrier (Ed.), Gifts and commodities: Exchange and Western Capitalism since 1700 (pp. 126144). London: Routledge.

Clarke, A. (1998). Window shopping at home: classified, catalogues and new consumer skills. In: D. Miller (Ed.), Material cultures (pp. 98-119). London: UCP.

Close, A. G. \& Kukar-Kinney, M. (2010). Beyond buying: Motivations behind consumers' online shopping cart use. Journal of Business Research, 63 (September-October), 986-92. Retrieved from http://www.journals.elsevier.com/journal-of-business-research. 
Cresswell, J. W. (1998). Qualitative Inquiry and Research Design: Choosing Among

Five Traditions. Thousand Oaks, CA: Sage.

Denegri-Knott, J. (2010). 'I want it now!: eBay and the acceleration of consumer

desire. Paper presented at the European Association for Consumer Research, Royal Holloway, Surrey.

Denegri-Knot, J. \& Zwick, D. (2012). Tracking prosumption on eBay. American

Behavioral Scientist, 56(4), 439-458. doi: 10.1177/0002764211429360

Denegri-Knott, J. \& Molesworth, M. (2010). Concepts and practices of digital virtual consumption. Consumption, Markets \& Culture, 13 (2), 109-132. doi:

$10.1080 / 10253860903562130$

Denegri-Knott, J., Watkins, R. \& Wood, J. (2012). Transforming digital virtual goods into meaningful possessions. In: M. Molesworth \& J. Denegri-Knott (Eds.), Digital virtual consumption (pp. 76-91). New York: Routledge.

Doubleclick (2011, July). The 1000 most visited sites on the web. Doubleclick. Retrieved from: http://www.google.com/adplanner/static/top1000/ Epp, A. \& Price, L. (2010). The storied life of singularized objects: Forces of agency and network transformation. Journal of Consumer Research, 36 (February), 820-837.

Foucault, M. (1976). The History of Sexuality Volume 1. England: Penguin Books

Foucault, M. (1977). Discipline and Punish: The Birth Of The Prison. London: Allen Lane.

Hand, M. \& Shove, E. (2007). Condensing practices: ways of living with the freezer. Journal of Consumer Culture, 7(1), 79-104. doi: 10.1177/1469540507073509 
Jenkins, R., Nixon, E. \& Molesworth, M. (2011).'JJust normal and homely’: The presence, absence and othering of consumer culture in everyday imagining', Journal of Consumer Culture, 11 (2), 261-281. doi: $10.1177 / 1469540511402446$

Kerrane, B. \& Bettany, S. (2011). The (post-human) consumer, the (post-avian) chicken and the (post-object) Eglu. European Journal of Marketing, 45 (11), 1746-1756. doi: 10.1080/0267257X.2012.698633.

Knorr Cetina, K.D. (1997). 'Sociality with objects: social Relations in post-social knowledge societies. Theory, Culture and Society 14(4), 1-30. Retrieved from: http://tcs.sagepub.com/

Knorr Cetina, K.D. (2001). Objectual practice. In: T. Schatzki, K. Knorr Cetina \& E.O. Savigny (Eds.), The practice turn (pp. 175-188). London: Routledge.

KZERO (2012, July). Virtual worlds: Industry and user data. KZERO. Retrieved from: http://www.kzero.co.uk/blog/category/universe-graph/]

Latour, B. (1992). Where are the missing masses? The sociology of a few mundane artifacts. In: W.Bijker \& J. Law (Eds.), Shaping technology/building society studies in sociotechnical change (pp. 225-28). Cambridge MA: MIT Press.

Latour, B. (2007). Reassembling the Social: An Introduction to Actor-Network-Theory, Oxford: OUP

Lehtonen, T.K. 2003. The domestication of new technologies as a set of trials. Journal of Consumer Culture, 3(3), 363-85.

McCracken, G. (1988). Culture and consumption. Bloomington, IN: Indiana University Press. 
Mintel (2012), Videogames and Consoles-UK, London: Mintel Group

Molesworth, M. \& Denegri-Knott, J. (2012). Digital virtual consumption. New York: Routledge.

Molesworth, M. (2009, May). Adults' consumption of videogames as imaginative escape from routine. Paper presented at the American Association of Consumer Research, San Francisco, CA.

Schatzki, T.R. (1996). Social practices: A Wittgensteinian approach to human activity and the social. Cambridge: Cambridge University Press.

Schatzki, T.R., Knorr-Cetina, K. \& Savigny, E.V. (2001). The practice turn in contemporary theory. London: Routledge.

Shields, R. (2000, April). Performing virtualities: Liminality on and off the net. Virtual Society. Retrieved from: http://virtualsociety.sbs.ox.ac.uk/events/pvshields.htm Shields, R. (2002). The Virtual. London: Routledge.

Shove, E. A., \& Pantzar, M. (2005). Consumers, producers and practices:

Understanding the invention and reinvention of Nordic walking. Journal of Consumer Culture, 5(1), 43-64. doi: 10.1080/09537321003714402.

Suthers, D. (2006). Technology affordances for intersubjective meaning-making: A research agenda for CSCL. International Journal of Computers Supported Collaborative Learning, 1(3), 315-337.

Stevens, L. \& MacLaran, P. (2005). Exploring the 'shopping imaginary': the dreamworlds of women's magazines. Journal of Consumer Behaviour, 4(4), 268-281. 
Tian, K. \& Belk, R. (2005). Extended self and possessions in the workplace. Journal of Consumer Research, 32 (2), 297-310.

Turner, V. (1988). The anthropology of performance. New York: PAJ Publications.

Thompson, C.J., Locander, W.B. \& Pollio, H.R. (1989). Putting consumer experience back into consumer research: The philosophy and method of existentialphenomenology. Journal of Consumer Research, 16 (September), 133-46.

Watson, M. \& Shove, E. 2008. Product, Competence, Project and Practice: DIY and the Dynamics of Craft Consumption. Journal of Consumer Culture, 8(1), 69-89. doi: 000207505400004

Zwick, D. \& Dholakia, N. (2006a). Bringing the market to life: screen aesthetics and the epistemic consumption object. Marketing Theory, 6(1), 41-62. Retrieved from http://mtq.sagepub.com/search/results?fulltext=detlev+zwick\&x=10\&y=12\& submit=yes\&journal_set=spmtq\&src=selected\&andorexactfulltext=and

Zwick, D. \& Dholakia, N. (2006b). The epistemic consumption object and post-social consumption: expanding consumer-object theory in consumer research. Consumption, Markets and Culture, 9(1), 17-43. doi: $10.1080 / 10253860500481452$ 